\title{
Longitudinal study of obesity in the National Survey of Health and Development
}

\author{
O STARK, E ATKINS, O H WOLFF, J W B DOUGLAS
}

\begin{abstract}
In a nationally representative cohort of 5362 children born in one week in March 1946 weights and heights were recorded at $6,7,11,14,20$, and 26 years. Overweight was defined as a weight that exceeded the standard weight for height, age, and sex by more than $20 \%$ (relative weight $>120 \%$ ). The prevalence of overweight was $1.7 \%$ and $2.9 \%$ in boys and girls respectively at 6 years; $2.0 \%$ and $3.8 \%$ at 7 years; $6.4 \%$ and $9.6 \%$ at 11 years; $6.5 \%$ and $9.6 \%$ at 14 years; $5 \cdot 4 \%$ and $6.5 \%$ at 20 years; and $12.3 \%$ and $11.2 \%$ at 26 years. The risk of being overweight in adulthood was related to the degree of overweight in childhood and was about four in 10 for overweight 7year-olds. Analysis of the data in the reverse direction showed that $7 \%$ and $13 \%$ respectively of 26 -year-old overweight men and women had been overweight at the age of 7 .

These results suggest that there is no optimal age during childhood for the prediction of overweight in adult life and that excessive weight gain may begin at any time. Overweight children are more likely to remain overweight than their contemporaries of normal weight are to become overweight.
\end{abstract}

\section{Introduction}

Obesity presents a serious health problem in Britain ${ }^{1}$ and most other developed countries. Because treatment is difficult and long-term results often disappointing more attention is being given to prevention. To improve our understanding of the

Institute of Child Health, London WC1N 1EH

O STARK, MD, part-time medical officer

O H WOLFF, MD, FRCP, Nuffield professor of child health

MRC Unit on Environmental Factors in Mental and Physical Illness, London

E ATKINS, MSC, formerly member of scientific research staff J W B DOUGLAS, BM, formerly director of unit natural history of obesity more information is needed, and this can be obtained only from a longitudinal study. Obesity in the adult may be preceded by obesity during childhood, but few studies $^{2-4}$ of this association have been reported because reliable data are difficult to obtain over this length of time.

A nationally representative cohort of British children born in 1946 and followed up in the National Survey of Health and Development provided information on height and weight during childhood, adolescence, and early adult life. The survey made it possible to estimate the prevalence of overweight at various ages, to assess the likelihood of an overweight child becoming an overweight adult, and to examine the extent to which the prevalence of overweight in adults might be reduced if effective prevention of overweight during childhood and adolescence was achieved. We report the results of the study.

\section{Subjects and methods}

The data on heights and weights were derived from the National Survey of Health and Development. ${ }^{5}$ The population studied consisted of 5362 children. All children born during the first week of March 1946 to the wives of non-manual workers and farm labourers and one-quarter of those born to wives of other types of manual workers and self-employed people were included. Illegitimate children and twins were excluded. The cohort was followed up from birth at intervals of two to five years. By the age of $26,291(5.4 \%)$ of the original sample had died, $517(9.6 \%)$ had been excluded because of emigration, and $605(11.3 \%)$ were untraceable or had refused to continue to cooperate in the study. Though refusals and failure to contact were slightly more common in the lowest social group, the sample remained closely representative of the original population and no attempt was made to adjust for differential losses. To adjust for the one-in-four sampling the children of the manual and self-employed groups were reweighted by a factor of four.

Heights and weights in this paper are expressed in inches and pounds because these measures were in common use during the period of study. Conversion of the data into the metric system seemed inappropriate and impracticable.

Heights and weights were measured at $6,7,11$, and 14 years by school doctors or nurses who were instructed to weigh the child in only his underclothes; at 20 and 26 years heights and weights were self-reported. About $80 \%$ of the sample responded at each follow-up, but complete information for all the ages was available for a smaller proportion of the subjects. 
The data were edited to eliminate errors of recording, reporting, and coding. Implausible values of height or weight were checked by plotting the subject's heights and weights on growth charts. ${ }^{6}$ When the height curve was well defined implausible values were replaced by a value estimated by smoothing the height curve graphically $(1 \%$ of measurements); otherwise the value was discarded $(0.5 \%$ of measurements). Implausible weights were also discarded ( $1 \%$ of measurements).

The accuracy of self-reported heights and weights was examined as part of a supplementary study ${ }^{7}$ carried out in 1977 on a subsample of 173 members of the survey living in the home counties, when they were 31 years old; self-reported heights and weights were compared with measurements taken by investigators using standardised equipment during the same visit. Self-reported weights were within $7 \mathrm{lb}$ of the measured value in $85 \%$ of the men and $96 \%$ of the women; self-reported heights were within two inches of the measured value in all women and $95 \%$ of the men. In both sexes the reported measurements underestimated the most severe degrees of overweight and underweight. This supplementary study suggested that the selfreported heights and weights might have led to an underestimate of the prevalence of overweight at 20 and 26 years, and its data may be used to estimate the extent of this bias. Systematic adjustment of the selfreported values at 20 and 26 years was considered to be unjustified, however, because the supplementary study was based on data obtained at the age of 31 .

\section{ASSESSMENT OF OVERWEIGHT}

An index of relative weight (weight expressed as a percentage of the standard weight for age, height, and sex) was used to express the degree of overweight. As in many other studies ${ }^{1}$ overweight was defined as a weight that exceeded the standard weight by $20 \%$. This definition has limitations because at different ages the same percentage overweight may have different implications for physical and emotional wellbeing. For instance, a 3-year-old toddler who weighs $30 \%$ over standard weight is less likely to suffer emotionally from his appearance and from being teased about it than a 9-year-old schoolboy or a 14year-old adolescent girl with a comparable degree of overweight. In some studies ${ }^{8}$ the term overweight is used for people whose weight is $10-20 \%$ above standard, and obese for those whose weight is more than $20 \%$ above the standard. In this study the terms overweight and obese were used synonymously, though we recognise that, strictly speaking, obesity implies an excess of body fat and that the degree of overweight and the excess of fat do not necessarily coincide.

The average weight for height, age, and sex, as derived from the data from the National Survey of Health and Development, was used as the standard. Since the relation of average weight to height is nonlinear a standard weight curve of the form $w_{s}=\operatorname{ch}^{p}$ was fitted $\left(w_{s}=\right.$ standard weight; $h=$ height; $c$ and $p=$ constants) to obtain an easily computable smooth curve of weight for height (fig 1), giving a relative weight equivalent to the power index $\left(w / h^{\mathfrak{p}}\right)$. The Quetelet body mass index, $w / h^{2}$, is of this type and has been recommended for assessing adult overweight. ${ }^{1}$ Newens and Goldstein ${ }^{9}$ and Cole, ${ }^{10}$ however, suggested that in childhood better results may be obtained by determining the value $p$ for each age by the relation of weight to height; in the

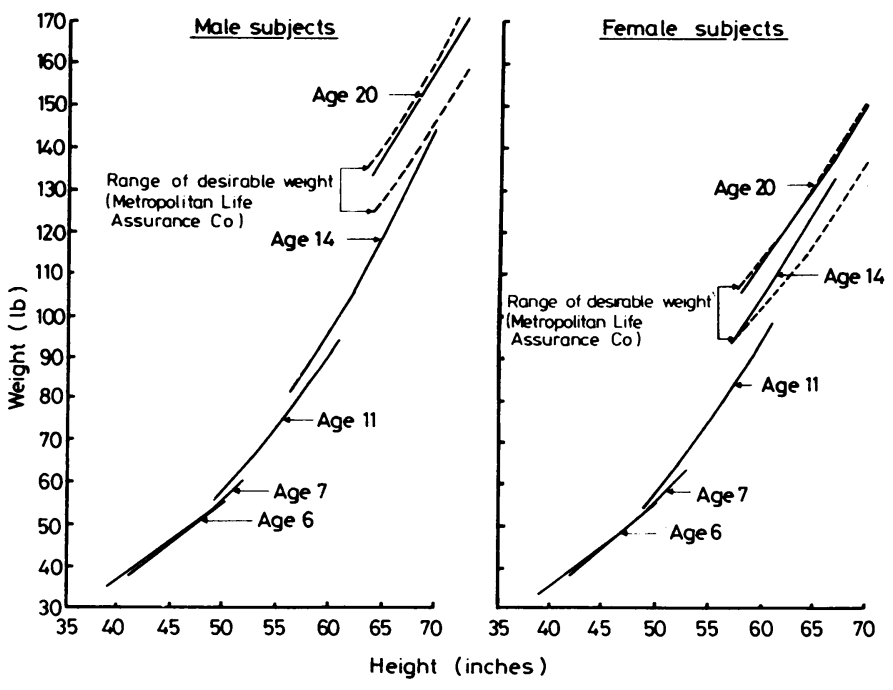

FIG 1-Standards of weight for height at specific ages.

Curves are given by $\log _{10}$ weight $=a+p \log _{10}$ height. For male subjects aged $6 \mathrm{a}=1 \cdot 2, \mathrm{p}=1.9 ;$ aged $7 \mathrm{a}=1 \cdot 2, \mathrm{p}=2 \cdot 0$; aged $11 \mathrm{a}=1 \cdot 2, \mathrm{p}=2 \cdot 4 ;$ aged $14 \mathrm{a}=1 \cdot 2, \mathrm{p}=2 \cdot 6$; and aged $20 \mathrm{a}=1 \cdot 4, \mathrm{p}=1 \cdot 8$. For female subjects aged 6 $\mathrm{a}=1 \cdot 2, \mathrm{p}=2 \cdot 0$; aged $7 \mathrm{a}=1 \cdot 2, \mathrm{p}=2 \cdot 2$; aged $11 \mathrm{a}=1 \cdot 1, \mathrm{p}=2 \cdot 6$; aged 14 $\mathrm{a}=1 \cdot 3, \mathrm{p}=2 \cdot 2 ;$ and aged $20 \mathrm{a}=1 \cdot 4, \mathrm{p}=1 \cdot 8$.

present study the values of $p$, though close to 2 , varied from 1.8 to 2.6 according to age and sex. The curves obtained by using this method correspond closely with those obtained in other studies.10 11

For adults a fixed standard may be preferable to an age-specific one. In this study average weight for height at $\mathbf{2 0}$ was used as the standard for 20 and 26 years, this value being close to the upper limit of the range of desirable weight given by the Metropolitan Life Insurance Company, ${ }^{12}$ whereas the value at 26 years lies above the upper limit of that range.

\section{Results}

PREVALENCE OF OVERWEIGHT

At 6 years of age the prevalence of overweight (relative weight $>120 \%$ ) was about $2 \%$ in boys and $3 \%$ in girls (table I). At 11 and 14 years the variance and positive skewness of the distribution had increased and the prevalence of overweight was about $6 \%$ in boys and $10 \%$ in girls. The larger variance of relative weight at 11 and 14 may have been partly an effect of growth during adolescence, when weight and height are less in phase with each other.

At 20 the variance of relative weight had decreased, but it rose again at 26 , when overweight was most prevalent $(12 \%$ in men and $11 \%$ in women). (These figures may even be an underestimate owing to the

TABLE I-Percentage distribution of relative weight by age

\begin{tabular}{|c|c|c|c|c|c|c|c|c|c|c|c|c|c|c|}
\hline \multirow{2}{*}{$\begin{array}{c}\text { Age } \\
\text { (years) }\end{array}$} & \multirow{2}{*}{$\begin{array}{c}\text { Total } \\
\text { No of } \\
\text { subjects* }\end{array}$} & \multicolumn{11}{|c|}{$\begin{array}{c}\text { Relative weight } \\
(\%)\end{array}$} & \multicolumn{2}{|c|}{$\begin{array}{c}\text { Prevalence of } \\
\text { overweight }\end{array}$} \\
\hline & & $<70$ & $71-80$ & $81-90$ & $91-100$ & $101-110$ & $111-120$ & $121-130$ & $131-140$ & $141-150$ & $151-160$ & $>160$ & Mean & SE $†$ \\
\hline \multicolumn{15}{|c|}{ Percentage of male subjects } \\
\hline $\begin{array}{r}6 \\
7 \\
11 \\
14 \\
20 \\
26\end{array}$ & $\begin{array}{l}4810 \\
4808 \\
4858 \\
4425 \\
4279 \\
4223\end{array}$ & $\begin{array}{r}0.1 \\
<0.1 \\
0.1 \\
0.2\end{array}$ & $\begin{array}{l}0.3 \\
0 \cdot 1 \\
1 \cdot 1 \\
1 \cdot 0 \\
1 \cdot 1 \\
0.9\end{array}$ & $\begin{array}{r}8.6 \\
7.6 \\
14.6 \\
14.9 \\
13.4 \\
8.1\end{array}$ & $\begin{array}{l}41 \cdot 0 \\
43 \cdot 2 \\
39 \cdot 9 \\
37 \cdot 6 \\
36 \cdot 8 \\
29 \cdot 6\end{array}$ & $\begin{array}{l}40 \cdot 2 \\
38 \cdot 2 \\
28 \cdot 1 \\
28 \cdot 5 \\
32 \cdot 4 \\
30 \cdot 3\end{array}$ & $\begin{array}{r}8 \cdot 2 \\
8 \cdot 7 \\
9 \cdot 9 \\
11 \cdot 3 \\
10 \cdot 7 \\
18 \cdot 7\end{array}$ & $\begin{array}{l}1 \cdot 4 \\
1.5 \\
3 \cdot 2 \\
4 \cdot 2 \\
3 \cdot 7 \\
8 \cdot 2\end{array}$ & $\begin{array}{l}0 \cdot 3 \\
0 \cdot 3 \\
2 \cdot 0 \\
1 \cdot 4 \\
1 \cdot 3 \\
3 \cdot 2\end{array}$ & $\begin{array}{r}<0.1 \\
0.2 \\
0.7 \\
0.6 \\
0.3 \\
0.6\end{array}$ & $\begin{array}{r}<0.1 \\
0.4 \\
0.1 \\
0.1 \\
0.2\end{array}$ & $\begin{array}{r}0.1 \\
0.3 \\
<0.1 \\
<0.1\end{array}$ & $\begin{array}{r}1 \cdot 7 \\
2 \cdot 0 \\
6 \cdot 4 \\
6 \cdot 5 \\
5 \cdot 4 \\
12 \cdot 3\end{array}$ & $\begin{array}{l}0.4 \\
0.4 \\
0.8 \\
0.9 \\
0.7 \\
0.9\end{array}$ \\
\hline \multicolumn{15}{|c|}{ Percentage of female subjects } \\
\hline $\begin{array}{r}6 \\
7 \\
11 \\
14 \\
20 \\
26\end{array}$ & $\begin{array}{l}4409 \\
4593 \\
4560 \\
4052 \\
3684 \\
4160\end{array}$ & $\begin{array}{r}0.3 \\
<0.1 \\
0.1\end{array}$ & $\begin{array}{l}0.6 \\
0.5 \\
2.6 \\
3.0 \\
2 \cdot 0 \\
1 \cdot 1\end{array}$ & $\begin{array}{l}10.4 \\
11.7 \\
18.6 \\
18.6 \\
16.4 \\
12.2\end{array}$ & $\begin{array}{l}42 \cdot 8 \\
40 \cdot 6 \\
33 \cdot 3 \\
30 \cdot 2 \\
33 \cdot 3 \\
31 \cdot 2\end{array}$ & $\begin{array}{l}34 \cdot 1 \\
33 \cdot 5 \\
25 \cdot 4 \\
26 \cdot 2 \\
29 \cdot 0 \\
28 \cdot 9\end{array}$ & $\begin{array}{r}9 \cdot 2 \\
10 \cdot 0 \\
10 \cdot 3 \\
12 \cdot 3 \\
12 \cdot 7 \\
15.4\end{array}$ & $\begin{array}{l}2 \cdot 1 \\
2 \cdot 6 \\
4 \cdot 5 \\
5 \cdot 4 \\
3 \cdot 2 \\
5 \cdot 8\end{array}$ & $\begin{array}{l}0 \cdot 4 \\
0 \cdot 6 \\
2 \cdot 5 \\
2 \cdot 2 \\
2 \cdot 0 \\
2 \cdot 5\end{array}$ & $\begin{array}{l}0.4 \\
0.3 \\
1.3 \\
0.6 \\
0.9 \\
1.2\end{array}$ & $\begin{array}{l}0.3 \\
0.8 \\
0.8 \\
0 \cdot 1 \\
1 \cdot 1\end{array}$ & $\begin{array}{l}0.1 \\
0.5 \\
0.6 \\
0.2 \\
0.7\end{array}$ & $\begin{array}{r}2.9 \\
3.8 \\
9.6 \\
9.6 \\
6.5 \\
11.2\end{array}$ & $\begin{array}{l}0.5 \\
0.5 \\
0.8 \\
0.9 \\
0.7 \\
0.9\end{array}$ \\
\hline
\end{tabular}

*Weighted numbers. 
error resulting from self-reporting of height and weight, and if an adjustment is made for this bias, based on the results of the supplementary study, ${ }^{7}$ the prevalences in women at 20 and 26 become $8 \%$ and $14 \%$ respectively, and in men $7 \%$ and $17 \%$.) The prevalence of overweight during childhood and adolescence was higher in girls but this difference was not apparent in the young adults.

\section{CORRELATION BETWEEN RELATIVE WEIGHTS AT VARIOUS AGES}

Table II shows the strength of the relations between relative weights at different ages by giving the correlation coefficients, all of which were positive; those for female subjects were higher than those for male subjects. As expected, the correlation decreased as the time interval lengthened.

\section{RISK OF BEING AN OVERWEIGHT ADULT}

Relative weight in the early school years correlated only weakly with relative weight at age 26 (table II), showing that relative weight

TABLE II-Correlations betwsen relative weight at various ages (figures in parentheses are weighted numbers on which correlations are based)

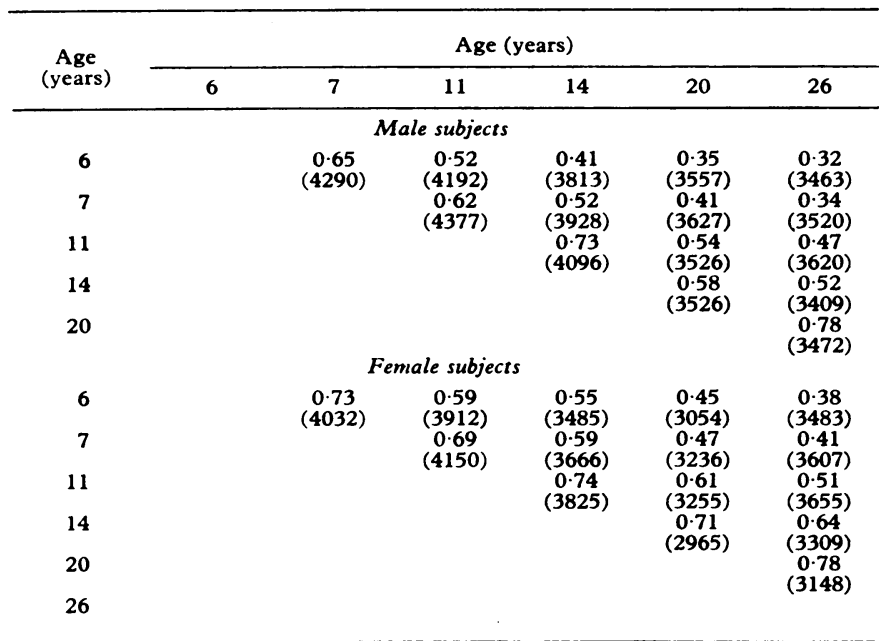

SE of correlation coefficients $\leqslant 0.02$ for male and female subjects. in the adult cannot be accurately predicted from relative weight in childhood. In men about $12 \%$ and in women about $17 \%$ of the variance in relative weight at 26 was predicted by relative weight at 7 years.

When giving a prognosis for individual children it is less important to be able accurately to predict relative weight in adult life than to estimate the likelihood of the child growing up to be an overweight adult. Table III shows the frequency distribution of relative weight at 7 and 26 years, giving the number of subjects in each $10 \%$ category of relative weight. The positive correlation already noted between relative weight at the two ages was reflected in the tendency for the subjects who at the age of 7 had been overweight (relative weight $>120 \%$ ) to be in one of the higher categories of relative weight at the age of 26. Whereas the risk of being overweight at 26 was low for children whose relative weight at 7 was less than $90 \%$, the risk increased to four out of $\mathbf{1 0}$ for those with relative weight exceeding $120 \%$. The risk of being a severely overweight adult (relative weight $>140 \%$ ) also rose with increasing relative weight at age 7 , being low when relative weight was below $120 \%$ and rising to one in four for girls and one in 10 for boys with relative weight above $120 \%$. Nevertheless, weight status at $\mathbf{2 6}$ often differed greatly from that at $\mathbf{7 \text { , and }}$ nearly half of the overweight 7-year-olds were of normal weight at age 26 (relative weight $<110 \%$ ).

The risk of being overweight at 26 was four in 10 for overweight 11 -year-olds and increased to five in 10 for overweight 14 -year-olds and to seven in 10 for overweight 20-year-old women and eight in 10 for 20-year-old men. At all ages studied the risk of being overweight as an adult declined with decreasing relative weight and was negligible for relative weight $<80 \%$.

Table IV gives the proportion of the variance in relative weight at age 26 that could be predicted from relative weights at earlier ages using a regression equation and shows that the predictive power of the multiple regression that included relative weights at all previous ages was only slightly better than that using only the most recent relative weight. This suggests that in attempts to predict adult relative weight the current degree of overweight of the child or adolescent provides almost as much information as may be obtained when relative weights at earlier ages are also known.

CHANGES IN RELATIVE WEIGHTS BETWEEN THE AGE OF 7 AND LATER AGES

Table $\mathrm{V}$ shows the risk of being overweight (relative weight $>120 \%$ ) at later ages for 7-year-old children according to their weight status. Children of 7 whose relative weight was below $100 \%$ showed only a slight risk of becoming overweight, whereas the risk for overweight 7 -year-olds of being overweight at later ages was considerable, falling from seven out of 10 at age 11 to four out of 10 at 20 and 26 years.

TABLE III-Frequency distribution of relative weights at 7 and 26 years (figures are numbers of subjects)

\begin{tabular}{|c|c|c|c|c|c|c|c|c|c|c|c|c|c|c|}
\hline \multirow{2}{*}{$\begin{array}{c}\text { Relative } \\
\text { weight }(0) \\
\text { at age } 7 \text { years }\end{array}$} & \multicolumn{11}{|c|}{ Relative weight ( $\%$ ) at age 26 years } & \multirow{2}{*}{$\begin{array}{c}\text { Total } \\
\text { No of } \\
\text { subjects * }\end{array}$} & \multicolumn{2}{|c|}{$\begin{array}{l}\text { Percentage overweight } \\
\text { at age } 26 \text { years }\end{array}$} \\
\hline & $<70$ & $71-80$ & $81-90$ & $91-100$ & $101-110$ & $111-120$ & $121-130$ & $131-140$ & $141-150$ & $151-160$ & $>160$ & & $\begin{array}{c}\begin{array}{c}\text { Relative } \\
\text { weight } \\
>120 \%\end{array}\end{array}$ & $\begin{array}{c}\text { Relative } \\
\text { weight } \\
>140 \%\end{array}$ \\
\hline $\begin{array}{c}71-80 \\
81-90 \\
91-100 \\
101-110 \\
111-120 \\
121-130 \\
131-140 \\
141-150 \\
151-160 \\
>160\end{array}$ & $\begin{array}{l}4 \\
4\end{array}$ & $\begin{array}{r}13 \\
23 \\
1\end{array}$ & $\begin{array}{r}43 \\
173 \\
63 \\
14\end{array}$ & $\begin{array}{r}1 \\
88 \\
589 \\
324 \\
60 \\
6\end{array}$ & $\begin{array}{r}4 \\
60 \\
393 \\
484 \\
82 \\
17 \\
2 \\
2 \\
8\end{array}$ & $\begin{array}{rr} & N \\
24 & \\
261 & \\
268 & \\
86 & 6 \\
6 & \\
1 & \end{array}$ & $\begin{array}{c}\text { Male subjec } \\
\qquad \begin{array}{c}17 \\
74 \\
133 \\
42 \\
14\end{array}\end{array}$ & $\begin{array}{r}27 \\
38 \\
32 \\
4 \\
4\end{array}$ & $\begin{array}{r}1 \\
11 \\
6 \\
4\end{array}$ & $\begin{array}{l}1 \\
4 \\
4\end{array}$ & 1 & $\begin{array}{r}6 \\
249 \\
1546 \\
1322 \\
327 \\
51 \\
10 \\
8 \\
1\end{array}$ & $\begin{array}{r}7 \\
7 \\
14 \\
26 \\
\end{array}$ & $\begin{array}{l}0 \cdot 1 \\
0.8 \\
3 \\
11\end{array}$ \\
\hline Total No* & 8 & 37 & 293 & 1068 & 1050 & 647 & 280 & 105 & 22 & 9 & 1 & 3520 & & \\
\hline $\begin{array}{c}71-80 \\
81-90 \\
91-100 \\
101-110 \\
111-120 \\
121-130 \\
131-140 \\
141-150 \\
151-160 \\
>160\end{array}$ & 4 & $\begin{array}{r}4 \\
18 \\
18 \\
1\end{array}$ & $\begin{array}{r}3 \\
100 \\
248 \\
73 \\
12\end{array}$ & $\begin{array}{r}5 \\
158 \\
556 \\
319 \\
84 \\
25\end{array}$ & $\begin{array}{r}4 \\
98 \\
367 \\
422 \\
123 \\
29 \\
5\end{array}$ & $\begin{array}{r}F^{F e} \\
28 \\
166 \\
226 \\
83 \\
13 \\
2 \\
4\end{array}$ & $\begin{array}{c}\text { male subje } \\
3 \\
59 \\
118 \\
33 \\
9 \\
1 \\
1\end{array}$ & $\begin{array}{r}4 \\
17 \\
24 \\
26 \\
7 \\
1 \\
1\end{array}$ & $\begin{array}{r}5 \\
14 \\
11 \\
5 \\
5 \\
4\end{array}$ & $\begin{array}{r}6 \\
10 \\
4 \\
1 \\
4 \\
\end{array}$ & $\begin{array}{l}5 \\
6 \\
8 \\
5 \\
4\end{array}$ & $\begin{array}{r}20 \\
418 \\
1456 \\
1210 \\
370 \\
97 \\
18 \\
6 \\
8 \\
4\end{array}$ & $\begin{array}{r}3 \\
7 \\
14 \\
18 \\
\end{array}$ & $\begin{array}{r}1 \\
2 \\
2 \\
2 \\
\\
26\end{array}$ \\
\hline Total No* & 4 & 41 & 436 & 1147 & 1048 & 526 & 224 & 80 & 44 & 29 & 28 & 3607 & & \\
\hline
\end{tabular}

$\underline{\underline{m}}$ 
Figure 2 shows changes in relative weight in individual children who were severely overweight (relative weight $>140 \%$ ) at 7 years and for whom data were available at at least four other ages. At 6 and 11 relative weight was high in all cases. In boys it tended to decline gradually after 11, and at 26 none of them was overweight though relative weight remained above average. In girls the changes were more variable and nearly all were still overweight at 26 .

\section{WEIGHT STATUS OF OVERWEIGHT ADULTS AT EARLIER AGES}

Reversal of the direction of the analysis showed that only a few of the adults who were overweight at 26 years had been overweight at 6 years (table VI). At ages 11 and 14 the proportion increased, three

TABLE IV-Percentage of variance in relative weight at age 26 predicted by relative weight at earlier ages

\begin{tabular}{lcc}
\hline \multicolumn{1}{c}{ Age } & Men & Women \\
\hline 6 & 10 & 15 \\
7 & 12 & 17 \\
11 & 22 & 26 \\
14 & 27 & 41 \\
20 & 61 & 61 \\
$6+7$ & 13 & 18 \\
$6+7+11$ & 24 & 31 \\
$6+7+11+14$ & 33 & 42 \\
$6+7+11+14+20$ & 61 & 65 \\
\hline
\end{tabular}

TABLE V-Prevalence of overweight (relative weight $>120 \%$ ) at later ages according to relative weight at 7 years

\begin{tabular}{ccccc}
\hline \multirow{4}{*}{$\begin{array}{c}\text { Relative weight } \\
\text { at age 7 years }(\%)\end{array}$} & \multicolumn{4}{c}{$\%$ of subjects overweight at age: } \\
\cline { 2 - 5 } & 11 & \multicolumn{1}{c}{ Male subjects } & 26 \\
\hline 80 & 0 & 0 & 0 & 0 \\
$81-90$ & $0 \cdot 3$ & 0 & 0 & 7 \\
$91-100$ & $0 \cdot 7$ & 2 & 4 & 7 \\
$101-110$ & 8 & 7 & 4 & 14 \\
$111-120$ & 22 & 24 & 15 & 26 \\
$>120$ & 70 & 53 & 43 & 43 \\
& & Female subjects & & \\
$<80$ & 0 & 0 & 0 & 0 \\
$81-90$ & $0 \cdot 8$ & 1 & 1 & 3 \\
$91-100$ & 2 & 3 & 4 & 7 \\
$101-110$ & 8 & 9 & 6 & 14 \\
$111-120$ & 30 & 26 & 8 & 18 \\
$>120$ & 71 & 57 & 37 & 41 \\
\hline
\end{tabular}

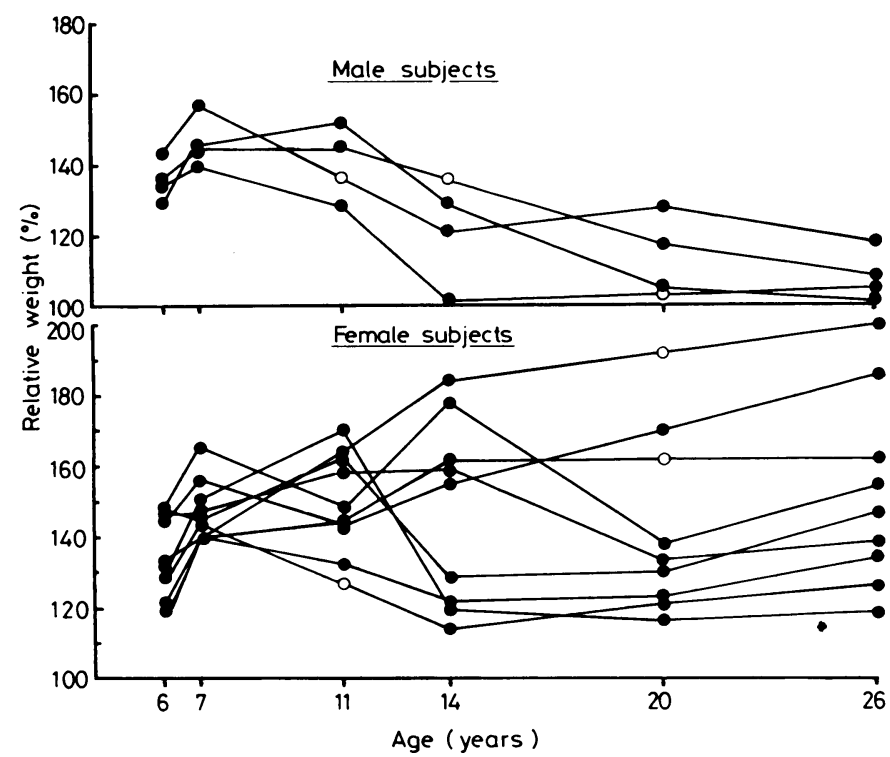

FIG 2-Changes in relative weight in four male and nine female subjects severely overweight (relative weight $>140 \%$ ) at 7 years $O=$ Relative weight not available.
TABLE VI-Relative weights at earlier ages of overweight 26-year-old subjects (figures are percentages)

\begin{tabular}{|c|c|c|c|c|c|c|}
\hline \multirow{2}{*}{$\begin{array}{c}\text { Age } \\
\text { (years) }\end{array}$} & \multicolumn{3}{|c|}{$\begin{array}{l}\text { Male subjects with } \\
\text { relative weight: }\end{array}$} & \multicolumn{3}{|c|}{$\begin{array}{l}\text { Female subjects with } \\
\text { relative weight: }\end{array}$} \\
\hline & $<100 \%$ & $101-120 \%$ & $>120 \%$ & $<100 \%$ & $101-120 \%$ & $>120 \%$ \\
\hline $\begin{array}{r}6 \\
7 \\
11 \\
14 \\
20 \\
26\end{array}$ & $\begin{array}{r}28 \\
29 \\
20 \\
17 \\
5 \\
0\end{array}$ & $\begin{array}{r}65 \\
64 \\
53 \\
56 \\
59 \\
0\end{array}$ & $\begin{array}{r}6 \\
7 \\
26 \\
28 \\
35 \\
100\end{array}$ & $\begin{array}{r}30 \\
28 \\
18 \\
11 \\
4 \\
0\end{array}$ & $\begin{array}{r}60 \\
59 \\
50 \\
43 \\
54 \\
0\end{array}$ & $\begin{array}{r}10 \\
13 \\
32 \\
45 \\
43 \\
100\end{array}$ \\
\hline
\end{tabular}

out of 10 boys and four out of 10 girls being already overweight at these ages.

\section{Discussion}

This study shows that correlations between relative weights in childhood and young adulthood are only weakly positive and that for many adults weight status is not determined in childhood. As expected, changes in relative weight during the years of childhood and adolescence were gradual, relative weight being more stable over shorter time intervals. The correlations found by Miller et $a l^{13}$ in a longitudinal study of children born in Newcastle agree closely with ours, and both studies show that as a child grows older and in particular during the second decade the accuracy with which adult weight status can be predicted improves. In a longitudinal study of skinfold thickness Hawk and Brook ${ }^{14}$ found somewhat higher correlations but nevertheless concluded that fatness in adults cannot be accurately predicted from measurements made when they were children.

The finding of positive correlations between relative weight at any two ages covered by our study means that the risk of being overweight as an adult is greater for overweight children and adolescents than for those of average or below average weight. The clinical impression that most severely overweight children (relative weight $>140 \%$ ) are still overweight in adolescence was confirmed, but our study showed that by no means all of those children and adolescents grew up into overweight adults. The survey procedure did not allow us to assess the extent to which treatment of severe overweight might have influenced the natural history.

Caution must be exercised in attempting to compare our data with those of other workers because of differences in sampling and in methods used for the assessment of overweight. Thus in the study of Abraham and Nordsieck $74 \%$ and $72 \%$ of $11-$ to 13-year-old overweight boys and girls respectively were still overweight as adults, whereas in our cohort only $40 \%$ of the overweight 11-year-old and $50 \%$ of the overweight 14-year-old children were still overweight at 26 years. This difference may be due to the small number in the American study or to an underestimate of the prevalence of overweight at 26 years in our study resulting from self-reporting of weight, or both.

A comparison of the findings of a Swedish study, ${ }^{15}$ in which relative weight was determined at 7 and $10 \frac{1}{2}$ years, with ours, in which the data refer to 7 and 11 years, shows close agreement with regard to the low risk for underweight 7-year-olds and the high risk for overweight 7-year-olds of being overweight at the older age. Whatever their relative weight at the age of 7 the Swedish children ran a somewhat lower risk of being overweight at the older age.

In our cohort the prevalence of overweight increased between the ages of 6 and 14. The increase was greatest between the ages of 7 and 11 , and nearly $70 \%$ of the overweight 11 -year-olds had not been overweight at the age of 7 . Measures aimed at preventing overweight would appear to be particularly appropriate for this age range. Our finding of a lower prevalence of overweight at 20 than at 14 years may be consistent with the observed reduction in the variance of weight for height between adolescence and early adulthood, which was also found by Cole ${ }^{10}$ 
and Van Wieringen." Bias resulting from self-reporting of weight at age 20 must, however, be taken into account when considering the lower prevalence at 20 , and when adjustment was made for this the decrease became smaller for the female subjects and was no longer apparent for the male subjects. After the age of 20 the prevalence of overweight rose again, and $64 \%$ of the overweight 26 -year-old men and $57 \%$ of the women had not been overweight at 20 .

Our findings suggest that even if treatment of overweight children during the first decade of life could prevent them from becoming overweight in young adult life the resulting reduction in the number of overweight adults would be less than $10 \%$. From the point of view of preventing adult overweight the second decade appears to be more important because $28 \%$ of men and $45 \%$ of women who were overweight at 26 years had been overweight at the age of 14 years.

To our knowledge this is the first study based on national data on the development of overweight between the ages of 6 and 26 years. The results suggest that there is no optimal age during childhood for the prediction of overweight in adult life and that excessive weight gain may begin at any time during childhood, adolescence, or young adult life. No specific pattern could be identified for the progression of overweight once established. The study confirmed that the overweight child carries a much greater risk of remaining overweight than his contemporaries of normal weight carry of becoming overweight and is more likely to become severely overweight. Because at the ages of 20 and 26 weight and height were self-reported the prevalence of overweight at these ages may have been underestimated. Nevertheless, the data presented probably reflect the general trends in weight over the period covered by the survey.

We thank Susan Cran and Rob Campbell for their help in preparing the data, Professor J R T Colley for his helpful comments, and Jean French for secretarial help.

\section{References}

1 Department of Health and Social Security/Medical Research Council Group. Research on obesity. Report. London: HMSO, 1976.

2 Mullins AG. The prognosis in juvenile obesity. Arch Dis Child 1958;33: 307-14.

${ }^{3}$ Charney E, Goodman HC, McBride M, et al. Childhood antecedents of adult obesity. Do chubby infants become obese adults ? $N$ Engl f Med 1976 ;295:6-9.

4 Abraham S, Nordsieck M. Relationship of excess weight in children and adults. Public Health Rep 1960 ;75:263-73.

5 Douglas JWB, Blomfield JM. Children under five. London: George Allen and Unwin Ltd, 1958.

- Tanner JM, Whitehouse RH, Takaishi M. Standards from birth to maturity for height, weight, height velocity and weight velocity: British children 1965. Arch Dis Child 1966;41:454-71, 613-35.

${ }^{7}$ Marmot MG, Page CM, Atkins E, Douglas JWB. Effect of breast-feeding on plasma cholesterol and weight in young adults. F Epidemiol Community Health 1980;34:164-7.

${ }^{8}$ Poskitt EME, Cole TJ. Do fat babies stay fat ? Br Med $\mathcal{f} 1977$;i :7-9.

- Newens EM, Goldstein H. Height, weight, and the assessment of obesity in children. British fournal of Preventive and Social Medicine 1972;26: 33-9.

${ }^{10}$ Cole TJ. A method for assessing age-standardized weight-for-height in children seen cross-sectionally. Ann Hum Biol 1979;6:249-68.

11 Van Wieringen JC. Secular changes of growth. Leiden: Netherlands Institute for Preventive Medicine TNO, 1972

12 Davidson S, Passmore R, Brock JF, Truswell AS. Desirable weights for men and women according to height and frame (modified from Statistical Bulletin, Metropolitan Life Insurance Company, 1959). In: Human nutrition and dietetics. Edinburgh: Churchill Livingstone, 1979.

${ }^{13}$ Miller FJW, Billewicz WZ, Thomson AM. Growth from birth to adult life of $\mathbf{4 4 2}$ Newcastle upon Tyne children. British fournal of Preventive and Social Medicine 1972;26:224-30.

${ }^{14}$ Hawk LJ, Brook CGD. Influence of body fatness in childhood on fatness in adult life. Br Med $\mathcal{F} 1979 ; \mathrm{i}: 151-2$.

${ }^{15}$ Mellbin T, Vuille J-C. Weight gain in infancy and physical development between 7 and $10 \frac{1}{2}$ years of age. British fournal of Preventive and Social Medicine 1976;30:233-8.

16 Cochran WG. Sampling techniques. New York: Wiley, 1953.

(Accepted 8 May 1981)

\section{SHORT REPORTS}

\section{Hemiballismus treated with sodium valproate}

Hemiballismus (proximal unilateral chorea) is a rare disorder characterised by involuntary proximal flinging movements of the limbs on one side of the body. Various treatments have been suggested. We present a patient who did not respond satisfactorily to conventional treatment but whose recovery was associated with the use of sodium valproate.

\section{Case report}

A 77-year-old man presented with the sudden onset of gross flailing movements of his right leg and, to a lesser extent, his right arm. On examination he was mentally alert but very distressed by the movements. There were distinct choreoathetotic movements of his right leg with less frequent uncontrolled movement of his right arm. His face was not affected. The movements were less apparent during sleep. Tendon reflexes were brisker in the right arm and leg than in the left, but both plantar responses were flexor. There was hypotonia on the right side. Blood pressure was 220/110 mm $\mathrm{Hg}$ supine. Right-sided hemiballismus was diagnosed, due to a presumed vascular lesion affecting the subthalamic nucleus (corpus Luysii) of the opposite side or its connections.

Tetrabenazine $25 \mathrm{mg}$ thrice daily produced no improvement in the abnormal movements, and excessive sedation became a problem. After three days tetrabenazine was replaced with haloperidol $5 \mathrm{mg}$ thrice daily increasing to $15 \mathrm{mg}$ thrice daily. Once again excessive sedation resulted without control of the choreoathetosis. Six days later thiopropazate was substituted with only slight therapeutic effect, and after five days' treatment with this drug at $5 \mathrm{mg}$ thrice daily, sodium valproate $200 \mathrm{mg}$ thrice daily was added. Within 24 hours his clinical signs were distinctly improved and he could walk with support. After five days of combined treatment thiopro- pazate was stopped and the improvement was fully maintained. He was discharged taking sodium valproate, walking independently and with almost complete control of his hemiballismus, two weeks after this drug was started.

After three months sodium valproate was reduced to $200 \mathrm{mg}$ twice daily; he remained independent and well, noticing occasional uncontrolled movements of his right leg when performing intricate movements with his hands -for example, when shaving.

\section{Comment}

Hemiballismus may occur as a result of any disease process affecting the area of the subthalamic nucleus. By far the most common lesion is cerebrovascular, especially in elderly patients. The movements tend to be severe with exhaustion of the patient, ${ }^{1}$ damage to the skin, and bruising of deeper tissues owing to repeated trauma. Hemiballismus may also occur as an adverse reaction to stereotactic surgery for Parkinson's disease. Tetrabenazine, haloperidol, thiopropazate, reserpine, and stereotactic surgery have been used to treat this condition with varying degrees of success. We have been unable to find a reference to the use of sodium valproate, but a closely related compound, dipropylacetic acid, has been used unsuccessfully in the management of Huntington's chorea. ${ }^{2} \gamma$-Amino butyric acid is reduced in the basal ganglia of patients with Huntington's chorea, and dipropylacetic acid raises central nervous system $\gamma$-amino butyric acid in animals. ${ }^{3}$

There is disagreement about the natural history of hemiballismus. ${ }^{1}$ The observed recovery in the case described may have been spontaneous, but we think that this is unlikely. The patient's hemiballismus had not responded to conventional drug treatment, which, moreover, led to excessive sedation. There was a rapid and dramatic improvement, however, with the introduction of sodium valproate, and the number of abnormal movements increased when the dose of sodium 